\title{
Root plasticity improves salt tolerance in different genotypes of lentil (Lens culinaris)
}

\author{
*Maria Rosaria Panuccio, *Barbara Logoteta, **F. De Lorenzo, **Adele Muscolo \\ *Department of Biotechnologies for Agri-Food and Environment Monitoring Agriculture Faculty, \\ "Mediterranea" University of Reggio Calabria, Salita Melissari-II LOTTO-89124 Reggio Calabria, Italy \\ e-mail: mpanuccio@unirc.it \\ **Department of Agricolture Forest System Management, Agricolture Faculty, \\ "Mediterranea" University Feo di Vito, 89126 Reggio Calabria, Italy
}

\begin{abstract}
Summary. Various morphological root parameters were tested in lentil seedlings in a genotype considered salt tolerant (Ustica) and in a salt sensitive one (Eston), grown on salinized soil. Apart from the root biomass production, two ecotypes showed contrasting root morphological responses and these might be partially responsible for dissimilar abilities to tolerate salinity.
\end{abstract}

Key words: root, plasticity, morphology, lentil.

\section{Introduction}

The phenotypic plasticity of plant is related to the ability to adapt its anatomy and morpho-functionality to environmental changes and it is expressed mainly by organs used for the uptake of resources, as leaves and roots (Smilauerova et al. 2002). Therefore the complexity and variability of radical system is the outcome of the root adaptation to soil heterogeneity (Waisel et al. 2002). Many abiotic stresses can induce alterations in plant morphology, such as root branching, total root length and root hair formation (Potters et al. 2007). These modifications can affect physiological characteristics of the root system, interfering with water uptake and nutrient supply by plants. The aim of this study was to investigate the salt effects on root growth and morphology of lentil seedlings grown in a salinized soil. In particular the microsperma landrace "Ustica", a genotype considered salt tolerant was investigated in comparison with a salt sensitive one (Eston). Various morphological root parameters such as length, volume, diameter and sur- face area were tested, as they are valuable parameters when describing and comparing root systems.

Structural and morphological differences in roots certainly play an essential role for nutrient and water uptake by plants from saline soil and the study of these parameters can help to determine different mechanisms underlying salt toxicity and the way plants can cope with saline conditions.

\section{Research methods}

Ustica and Eston seeds were germinated in a sandy-loam soil previously equilibrated with different salt concentrations: $0,50,100$ and $200 \mathrm{mM} \mathrm{NaCl}$. The pots were set up in a growth chamber at $18 / 20^{\circ} \mathrm{C}$ (night/day) with $16 \mathrm{~h}$ photoperiod and $70-80 \%$ relative humidity. The medium was maintained at a constant humidity by adding distilled water. After 3 weeks, plants were harvested, root and shoot weight was recorded. Parameters of root morphology were 

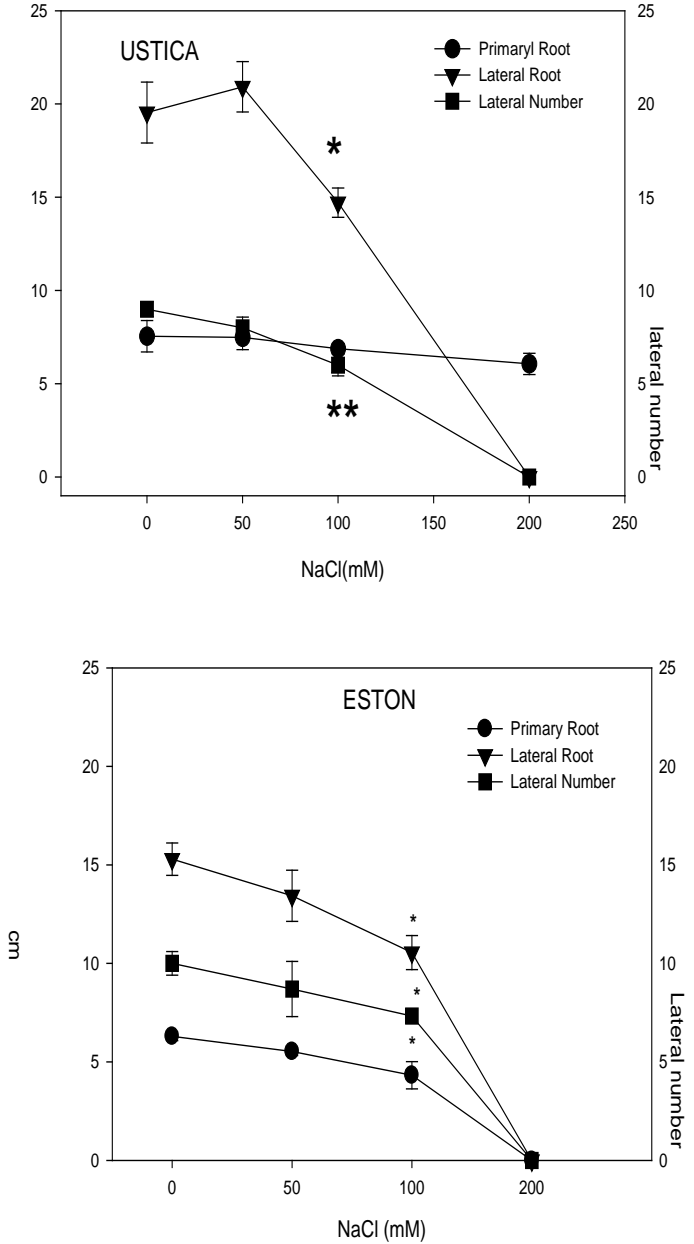

Figure 1. Effects of salinity $(0-200 \mathrm{mM} \mathrm{NaCl})$ on primary and lateral root length and on lateral number of Eston and Ustica plants

analysed using the WinRHIZO image analysis system (Regent Instruments, Quebec, Canada).

\section{Results and discussion}

Eston control seedlings showed a higher root biomass, but a lower lateral root length in comparison with Ustica plants (Fig. 1). Apart from root biomass production, the parameter "root length" is considered more important than the "root weight" to indicate the root functionality, because it expresses the potential for solute and water uptake (Ryser 2006). Under salinity the root development resulted inhibited because of a reduced availability of photosynthates from shoots and to counter water stress and ion toxicity due to the salt around the root. In Eston seedlings exposed to $100 \mathrm{mM} \mathrm{NaCl}$, the length and the number of primary and lateral roots were significantly reduced and, at $200 \mathrm{mM}$ of
Table 1. Analysis of variance of the effect of $\mathrm{NaCl}$ concentration $(0-200 \mathrm{mM})$ on the primary and lateral root length, surface area, volume and average diameter of Eston and Ustica lentil seedlings (plant)

\begin{tabular}{|l|c|c|c|c|}
\hline \multicolumn{4}{|c|}{ PRIMARY ROOT } \\
\hline \multicolumn{4}{|c|}{ Independent Variable } \\
$\begin{array}{c}\text { Dependent } \\
\text { variable }\end{array}$ & $\mathrm{NaCl}$ & plant & $\begin{array}{c}\text { Plant } \mathrm{x} \\
\mathrm{NaCl}\end{array}$ & $\mathrm{R}^{2}$ \\
\hline Length & $0.363^{\text {n.s. }}$ & $16.509^{* *}$ & $1.242^{\text {n.s. }}$ & 0,799 \\
\hline Surface Area & $0.451^{\text {n.s. }}$ & $0.062^{\text {n.s. }}$ & $2.067^{\text {n.s. }}$ & 0.546 \\
\hline Volume & $0.948^{\text {n.s. }}$ & $695,8^{* * *}$ & $0.948^{\text {n.s }}$ & 0.992 \\
\hline Average Diameter & $0.496^{\text {n.s. }}$ & $36.903^{* * *}$ & $0.245^{\text {n.s. }}$ & 0.881 \\
\hline
\end{tabular}

\begin{tabular}{|c|c|c|c|c|}
\hline \multicolumn{5}{|c|}{ LATERALS } \\
\hline \multicolumn{5}{|c|}{ Independent Variable } \\
\hline $\begin{array}{c}\text { Dependent } \\
\text { variable }\end{array}$ & $\mathrm{NaCl}$ & plant & $\begin{array}{c}\text { Plant x } \\
\mathrm{NaCl}\end{array}$ & $\mathrm{R}^{2}$ \\
\hline Length & 42.201* & $102,2 * *$ & $0.250^{\text {n.s. }}$ & 0.798 \\
\hline Surface Area & $2.273^{\text {n.s. }}$ & $0.127^{\text {n.s. }}$ & $0.066^{\text {n.s. }}$ & 0.535 \\
\hline Volume & $0.063^{\text {n.s. }}$ & $648.72 * * *$ & $0.004^{\text {n.s. }}$ & 0.991 \\
\hline Average Diameter & $0.057^{\text {n.s. }}$ & $20.538 * * *$ & $0.005^{\text {n.s. }}$ & 0.795 \\
\hline
\end{tabular}

Numbers represent $\mathrm{F}$ values at $5 \%$ level; n.s. not significant; $* 0.01<\mathrm{p}<0.05 ; * * 0.001<\mathrm{p}<0.01 ; * * * \mathrm{p}<0.001$

$\mathrm{NaCl}$, the plant growth was completely inhibited. For both genotypes, the length of lateral roots was more affected than that of primary roots (Fig. 1). In Ustica seedlings the emergence of laterals from primary roots was inhibited in presence of $200 \mathrm{mM} \mathrm{NaCl}$. The lateral root shaping is considered a prime example of developmental plasticity because both, number and length of lateral roots, are highly responsive to external cues.

Analysis of variance evidenced that root length was significantly affected by salinity (Tab. 1). Apart from effects of salinity, lateral roots of Ustica are longer and finer, having lower average diameter values. Conversely, Eston lateral roots are thicker and shorter in comparison with Ustica seedlings. The difference of root volume between two cultivars is due to different diameter values. Furthermore, when salinity increases a significant decrease of root volume occurs in Eston seedlings, but root volume of Ustica resulted unaffected. 
The root diameter value defines the volume of soil which can be exploited by roots by investing a given amount of photosynthates. Roots with a smaller root diameter can contact a larger soil volume per unit root surface area, however the maintenance carbon cost of producing finer roots may be higher as these will have be replaced more frequently (Fitter 1991). Root diameter distribution (data not shown) is usually expressed as the mean diameter but sometimes it does not necessarily characterize a response of root system structure adequately. In fact, fine and coarse roots show different responses and the diameter changes of larger roots have minimal impact on their ability to function.

Structural and morphological differences in roots certainly play an essential role for nutrient and water uptake by plants from saline soil and, apart from the effects on root biomass production, contrasting root morphological responses of ecotypes to salt treatments might be partially responsible for dissimilar abilities to tolerate salinity.

\section{References}

Fitter A. H., 1991, Characteristics and functions of root systems, [in:] Plant Roots, The Hidden Half, Marcel Dekker, Inc., New York: 3-25.

Potters G., Pasternak T. P., Guisez Y., Palme K. J. \& Jansen A. K., 2007, Stress induced morphogenic responses: growing out of trouble? Trends in Plants Science 12: 98-105.

Ryser P., 2006, The mysterious root length, Plant and Soil 286: 1-6.

Smilauerova M. \& Smilauer P., 2002, Morphological responses of plant roots to heterogeneity of soil resources, New Phytologist. 154 (3): 703-715.

Waisel Y. \& Eshel A., 2002, Functional diversity of various constituents of a single root system, [in:] Y. Waisel, A. Eshel, U. e Kafkafi (eds.), Plant Roots: the hidden half, Marcel Dekker, Inc., New York: 157-174. 